\title{
Social Studies Teachers' Difficulties in Assessing Social Skills
}

\author{
Supianto $^{1, *}$, Kumaidi $^{2}$, Yoyon Suryono ${ }^{3}$ \\ ${ }^{1}$ Department of Educational Research and Evaluation, Yogyakarta State University, Indonesia \\ ${ }^{2}$ Faculty of Psychology, Muhammadiyah University of Surakarta, Indonesia \\ ${ }^{3}$ Department of Nonformal Education, Yogyakarta State University, Indonesia
}

Received March 19, 2020; Revised April 3, 2020; Accepted April 19, 2020

Copyright $\mathrm{O} 2020$ by authors, all rights reserved. Authors agree that this article remains permanently open access under the terms of the Creative Commons Attribution License 4.0 International License

\begin{abstract}
Social skills can determine the success and failure of a person. However, to detect social skills is not easy. This study aims to describe the teachers' difficulties in Social Studies subject in assessing students' social skills and the factors that cause these difficulties. This research uses a qualitative approach with a phenomenology method. Data were collected using questionnaires, in-depth interviews, and focus group discussion with 20 Social Studies teachers spread in 20 Junior High Schools in 10 provinces throughout Indonesia. The data have been collected in the form of an interview script with the research subject. The data is then analyzed and brings up several specific themes. The results of this study indicate that there are at least several factors that affect the difficulties of Social Studies teachers in assessing students' social skills. First, teachers' educational qualifications are mostly not from Social Studies education but from various social science backgrounds. Second, the teacher's difficulties are in identifying social skills material in Social Studies. The first factor influences this. Third, the teacher has not carried out the core activities of the learning process on social skills such as planning, learning, and assessment. Fourth, teachers are not familiar with social skills constructs and indicators, time constraints, limited choice of instruments, and teacher and student's ratios contribute to these difficulties. This study recommends that social skills become the core of Social Studies, teachers must have appropriate qualifications, and further research needs to be done to develop social skills assessment instruments.
\end{abstract}

Keywords Social Skills, Social Studies, Assessment

\section{Introduction}

Social skills have been the focus of research in the field of Social Studies over the past decade [1-5]. Increased attention to social skills is based on several research results showing that social skills affect many aspects of the child. Lack of social skills is related to social isolation [6,7], bullying, aggressive, and anti-social [8-11]. Besides, social skills can also enhance friendship [12], school learning achievements $[12,13]$, and the success of later childhood [14].

Social skills are defined as socially acceptable behaviors that enable a person to interact positively with others [15]. More specifically, Gresham, Elliott, Newcomer, \& El [16] outlines the definition of social skills into three senses. First, peer acceptance, which is acceptable or popular among peers, is considered socially skilled. Second, behavioral description, a specific behavior that maximizes the likelihood of maintaining reinforcement or reducing the probability of punishment from a person's social behavior. Third, social validity, behavior in certain situations that can be used to predict the life of someone in the future. The definition can be used as a guide in describing the indicators related to social skills.

Because of the importance of social skills, researchers develop the models of intervention and teaching to improve children's social skills. Elkskin \& Elksnin [15] develop strategies to improve social skills in children with behavioral and learning problems. Tsangaridou, Zachopoulou, Liukkonen, Gråstén, \& Kokkonen [17] developed a method of developing students' social skills by involving parents as partners, both in teaching and home assessments. Espelage, Rose, \& Polanin [18] developed social and emotional learning programs to improve the prosocial attitudes as well as the academic ability of children with disabilities at the secondary school level. Gottman [6] developed a social skills teaching program for children who are alienated from their peers.

Besides the intervention and teaching models, there are also several methods of social skills assessment [19-25]. 
Gresham, Elliott, Newcomer, \& El [16] identifies children who lack social skills and involve parents, teachers, and peers in the assessment process. While Dodge, McClaskey, \& Feldman [26] introduced the Situational Approach. This approach is as well as a critique of existing methods, and more emphasis on the social context that underlies the attitude of children.

Both the intervention model and the social skill assessment have been developed. Both are designed separately from the subject matter usually taught in the school. Social skills should be a basic competence of existing subjects, especially Social Studies, which contain not only material on social knowledge but also values that can be applied by students [4]. Morris, McGuire, \& Walker [4] have undertaken the efforts to integrate social skills into Social Studies subjects, but their use is limited to children with disabilities.

The 2013 curriculum mandates that Social Studies lesson is as one of the subjects to be taught at the Junior High School level. The issue of Social Studies is the integration of historical, sociological, geographical, and economical materials that encompasses all human activities in space and time [27]. Such materials contain social values such as integration, cooperation, and tolerance [28].

Integrating social skills into Social Studies, both in the learning process and in the assessment, will provide students with the opportunity to learn and practice authentically and meaningful social skills [4]. However, in reality, Social Studies teachers do not assess social skills. This was reinforced by the FGD results and interviews of 20 Social Studies teachers who were in 20 junior high schools spread across ten provinces in Indonesia. From the FGD results and obtained interviews information that so far, they only assessed the cognitive aspects of students' social knowledge, while students' social skills are neglected.

The fact that Social Studies teachers do not assess their students' social skills is questionable. Considering that social materials covering social knowledge include more applicable social skills for students to apply in their life, at school and at home and in their society. Besides, social skills assessment methods have also been available even though they have not been integrated into Social Studies subjects, but can still be modified and adapted to assess students' social skills on Social Studies subjects. This research needs to be done to answer the question "How is the perception of Social Studies teachers about social skills? Why do the teachers not assess social skills? What are the constraints of teachers in conducting social skills assessment?"

The answer to the above research question can be used as a reference for designing the model and instrument of social skill assessment on the subject of Social Studies. Besides, knowing the constraints and difficulties of teachers in conducting social skills assessments can be used as a reference to create a social skills assessment training program for teachers. Thus, the assessment of social science does not stop at the cognitive aspect that is shown with excellent value on formative and summative tests but also involves more relevant elements, i.e., social skills.

\section{Methods}

This research uses a qualitative approach with a phenomenology method. This research seeks to understand the difficulties faced by teachers in assessing the students' social skills. The subjects consisted of 20 teachers of Social Studies of Junior High School scattered in 10 provinces in Indonesia. Teachers selected as research subjects are teachers with master educational qualifications in Social Studies and teachers who have certified educators.

Data collection is done through a questionnaire, focus group discussion (FGD), and in-depth interviews by using social media (WhatsApp) as the ingredients. In general, the questions in the questionnaire included the social studies of teacher's academic qualifications, the teacher's ability to identify social skills material, the teacher's activities in teaching social skills, and the factors that caused the teacher's difficulty in assessing social skills. Similar questions are also used as a basis for conducting in-depth interviews.

FGDs are conducted within the WhatsApp group to describe the common problems faced by teachers in assessing students' social skills. After the FGD, researchers conducted an in-depth interview with the subject individually through the WhatsApp account. In-depth interviews are conducted to ensure the credibility of the data that has been obtained.

During the data collection, either through FGD or deep interview, the researcher is as well as a role as a research instrument. Researchers strive to be responsive and adaptable, emphasize wholeness, base themselves on extending knowledge, processing data as soon as possible, and taking advantage of opportunities for classification. The interview guide is used to facilitate the process of data collection. The interview guide consists of components that include Social Studies materials related to social skills, integration of social skills into social science, social skills assessment models. The process of data analysis as a whole involves trying to interpret data in the form of text and images obtained from the data collection through WhatsApp. In this study, researchers adopted Creswell's data analysis techniques consisting of several interconnected stages: (1) processing and preparing data for analysis. This step involves transcribing interviews, scanning material, sorting through, and organizing the data into different types; (2) reading the entire data. The first step is to build a general sense of the information obtained and reflect on its overall meaning; (3) analyzing more 
detail by coding data. Coding is the process of processing material or information into segments of writing before entering it; (4) applying the coding process to describe the settings, the people, the categories, and the themes to be analyzed. The coding process is applied to create a small number of issues or types; (5) re-describing the problems that have been made in the narrative as research reports; and (6) interpreting the data.

\section{Results and Discussion}

An understanding of the difficulties of social studies teachers in assessing students' social skills is obtained through data from questionnaires, FGDs, and in-depth interviews. All data is analyzed and broken down into four main themes, namely: academic qualifications, identification of social skills material, teachers' perceptions about teaching social skills, and the difficulties in assessing social skills.

\subsection{Educational Qualifications of Social Studies Teachers}

The government, through the Ministry of National
Education, made changes to the curriculum, from KBK to KTSP Curriculum. This curriculum change affects all aspects of education, as well as in Social Studies lessons. Before the change, Social Studies was taught separately. At that time, there are three lessons that are categorized into Social Studies, namely history, economics, and geography. After the curriculum changes, the three subjects plus sociology were integrated into one field of study, which came to be known as Integrated Social Studies. In 2013, the government re-make the change of curriculum into Curriculum 2013 (K-13). This change did not have much impact on the field of Social Studies. This field is still taught in an integrated manner.

The change of curriculum becomes a necessity in improving the quality of education. However, any change is also not out of trouble. Similarly, the curriculum changes, both on KTSP and K-13, leave problems with Social Studies teachers. As it is known, teachers who are ultimately forced to teach the field of Social Studies have educational qualifications from various social science backgrounds, including history education, economic education, and geography education.

Based on the data obtained from the questionnaire, obtained information about the qualifications of the IPS teacher education is visualized as follows.

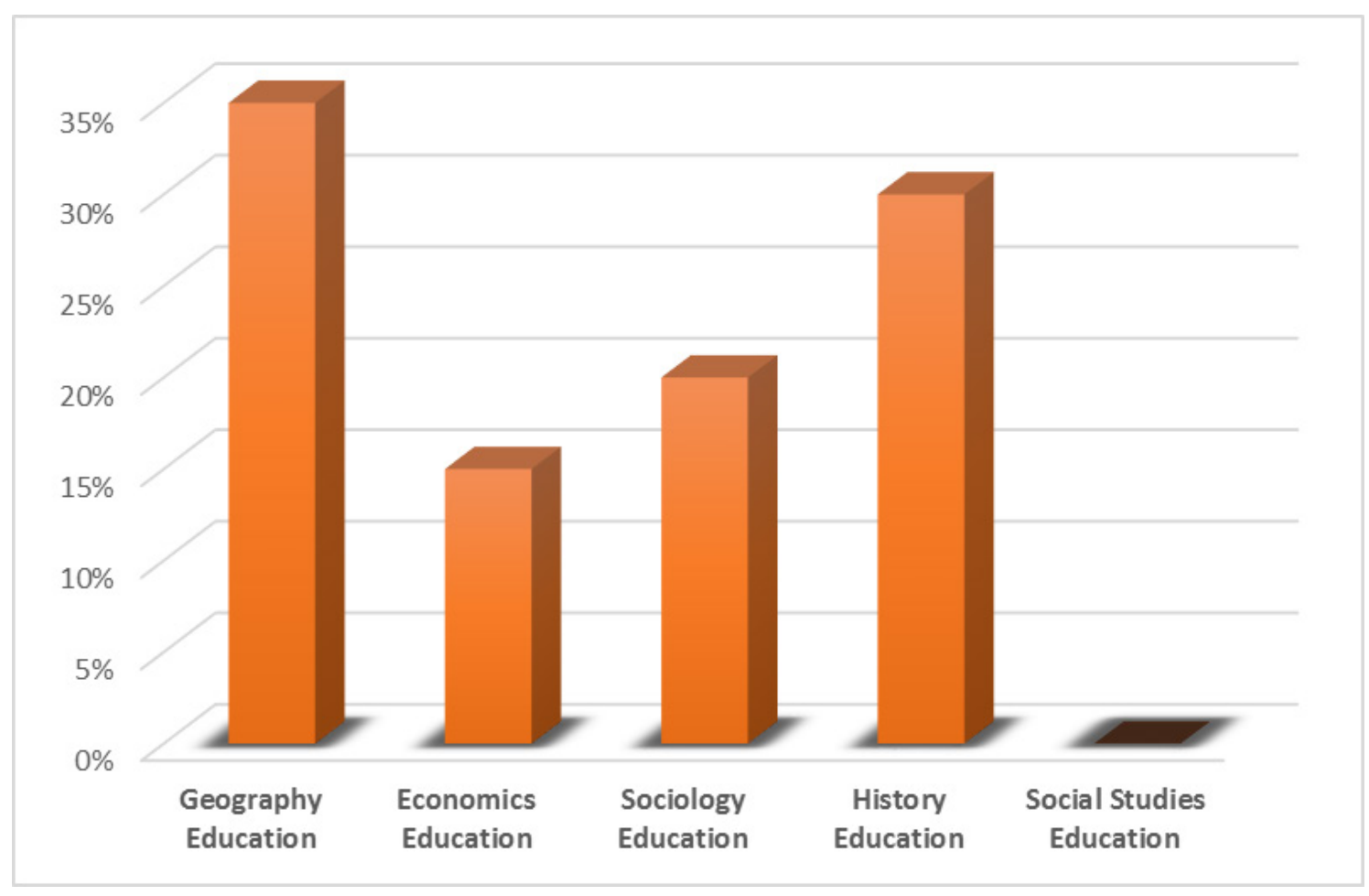

Figure 1. Educational Qualifications 
Based on Figure 1 above, information is obtained that social studies teachers have different social science educational backgrounds, most of them from geography education and history education, others are sociology education and economics education. Of the 20 social studies teachers interviewed, none of the social studies teachers had social studies education qualifications. That is, all social studies teachers teach subjects that are not their area of expertise. The results of the following interview confirmed this.

"My academic qualifications are historical education ..." (S3, S7)

"During my undergraduate degree, I majored in economics because I wanted to be an economics teacher ..." (S2)

"When the civil servant selection, I choose the position according to my department, namely geography ...". (S10).

The field of Social Studies is an integration of historical, economic, sociological, and geographical subjects. However, the topics are mostly unlike Social Studies because Social Studies are more integrative thematic. This curriculum changes not only give teachers difficulties because they have to teach subjects that do not fit their academic qualifications but also create gaps among the teachers themselves due to the reduced number of lessons. For certified teachers, this will have an impact on the dismissal of their certification allowance.

The government sees this as a severe problem that must be addressed immediately. In 2012, the government sought to adjust teachers' education qualifications with curriculum changes. This adjustment is made by providing scholarship Social Studies for teachers with a social science education background to pursue the postgraduate Social Studies field. However, the award was stopped in 2015. Of course, not all Social Studies teachers have the opportunity to get the graduate scholarship.

"I am lucky to qualify for Social Studies postgraduate scholarship selection in 2013 ..." (S10)

"There are still many of my friends who are interested in continuing education to postgraduate Social Studies. Unfortunately, the scholarship program has stopped ..." (S7, S9)

Adjustment of Social Studies teacher education qualification does not necessarily overcome the obstacles faced by teachers in integrating Social Studies lessons. Based on the acknowledgment of teachers who have completed their postgraduate education, in fact, at the level of postgraduate they do not get much knowledge about Social Studies, because their lecturers also have no educational qualifications Social Studies, but have the educational background of sciences social such as history, economics, geography, and sociology.

\subsection{Identification of Social Skills Material}

The Social Studies subjects taught at the junior level are an integration of historical material, economics, geography, and sociology. The four elements previously taught separately are then referred to as Integrated Social Studies. Social Studies not only contains social knowledge that stops in the cognitive domain but also includes more applicable values that can be applied directly by students in their life, both at school and home. The applicative benefits of Social Studies are referred to as social skills.

The integration of social science materials into integrated Social Studies makes the scope of this field of study extensive. Among these materials, there are those who emphasize only the cognitive aspect of such material as history that provides knowledge of past events. In addition, there are also materials that are applicable to the social life of students, both at school and at home. These applicative materials provide life skills for students about ways to socialize, interact with others, and understand others or better known as social skills.

The 2013 curriculum mandates four core competencies students must possess, namely spiritual attitude competence, social attitude competence, knowledge competence, and skill competence. Social skills are part of the other competences, namely the ability of social attitudes. Social skills are not explicitly stated as the title of a chapter in the Social Studies book. However, social skills are an inherent value contained in the subject matter of Social Studies. Therefore, the teacher's clarity must identify materials that contain social skills values.

One item that was asked in the questionnaire was how severe the teacher was in identifying social skills material. In visual terms, respondents' answers are displayed in the form of the picture below.

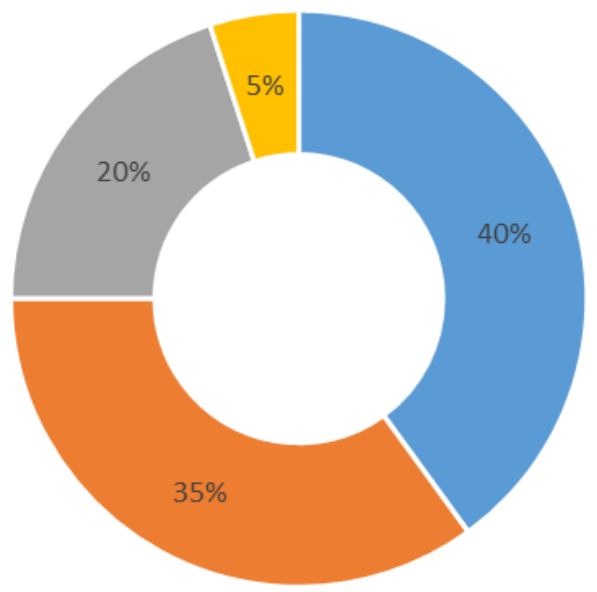

- Very Difficult n Difficult = Easy = Very Easy

Figure 2. Identifying Social Skills Material 
Based on Figure 2 above, information is obtained that $40 \%$ and $35 \%$ of social science teachers consider that identifying social skills material is very difficult and difficult. Only $20 \%$ and $5 \%$ of teachers consider this easy and very easy. The difficulty of social studies teachers in identifying material related to social skills is described through the following interview excerpt. "In my opinion, when students understand the social science materials I teach, he has the capital to practice social skills ..." (S18, S20)

The problem is not as simple as just teaching children social knowledge, then hoping that they will have the social skills of the knowledge they get. From the above interview result, it appears that the teacher has not been able to identify the social skills in the taught material. Even further, the teacher also cannot distinguish between social skills and social knowledge.

"Social Studies also includes historical material that can provide the values of nationalism ..." (S12, S17)

"In the sociology subgroup, there is a matter of social interaction. This may be part of social skills ..." (S9)

Referring to the definition developed by the National Council of Social Studies (NCSS), social skills have at least some indicators, including skills in obtaining information, skills related to social relations and participation in society, communication skills with others, and self-control. Following the above interview quotation that the social skill material contained in Social Studies lessons among them is social interaction. Social interaction materials teach social skills to students about ways to relate to others, respect others, and place themselves in positions that are acceptable to others and the environment.

\subsection{Teacher Activities in Teaching Social Skills}

Some researchers develop intervention models or social skills teaching that is separate from the usual subject matter taught in schools such as Social Studies lessons $[6,15,17,18]$. That is, the learning of social skills is designed as a separate program focused on developing children's social skills. Social Studies subject matter has covered social skills, so the intervention model need not be designed separately from existing lessons. Intervention models that have been developed previously can be adopted for the social teaching needs of Social Studies subjects.

From the questionnaire given to respondents, there were six items asking about social skills learning activities. The six items include:

Table 1. Social Skills Learning Activities

\begin{tabular}{|l|l|}
\hline No. & Items \\
\hline 1 & Plan social skills learning \\
\hline 2 & Teah social skills material \\
\hline 3 & Observe student behavior during learning \\
\hline 4 & Identify students' social skills \\
\hline 5 & Using the real-life as an example of social skills \\
\hline 6 & Use student social skills data to make decisions \\
\hline
\end{tabular}

Respondents were asked to give a score of 1-4 of all items, where $1=$ never, $2=$ seldom, $3=$ often, $4=$ always. Respondents' answers to these six items are visualized in the form of a percentage below.

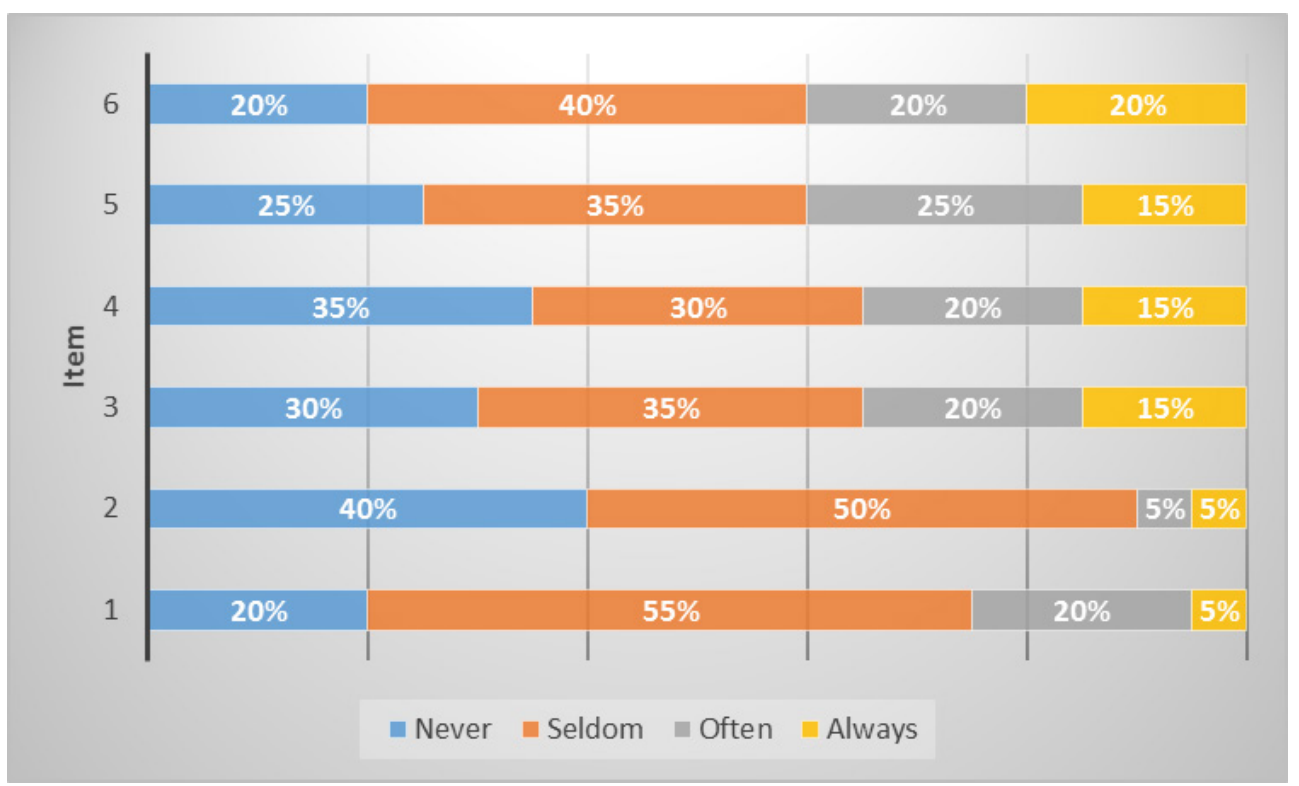

Figure 3. Social Skills Learning Activities 
Figure 3 above provides information about learning activities related to social skills material. Based on this picture, it is known that most social studies teachers never have or rarely do learning activities that lead to an increase in students' social skills. After the researcher obtained the data above, the researcher attempted to explore the causes of this through in-depth interviews with respondents. The following are some excerpts from the interview with respondents.

"Social skills are closely related to morals, this being the domain of Civics and Religious Studies...(S1, S7)."

The above interview quotes illustrate to us that so far, social skills are not considered part of the Social Studies lesson, but are the responsibility of other lessons. It also indicates that during this time, Social Studies teachers do not teach social skills to students. So who has actually been responsible for teaching social skills, who handles children with social behavior problems, and how to deal with them? The description of the question is implied from the following interview quotes.

"Children with social problems, both at school and home, are usually directly handled by BK teachers ..." (S13, S14)

"Teacher BK provides punishment by school rules, such as giving suspension to children ..." (S6, S18)

The approaching model to deal with children who have social problems can not only be done by giving punishment in the form of suspension, because this will only reinforce the confidence of the child and also his friends so that the child is in trouble. This is similar to what Dodge, McClaskey, \& Feldman [26] suggest that a more personal approach is needed to understand their problems. Dodge, McClaskey, \& Feldman [26] suggest using situational strategies, i.e., approaches that place more emphasis on social context as the experience of children against the backdrop of their low social skills. To accomplish the goal, it is necessary to design an assessment instrument design that will be used to identify not only students who lack social skills but also the underlying context. Thus, by knowing the background of the attitude shown by the child, an appropriate approach can be done to provide treatment to improve the social skills of the child.

\subsection{The Difficulties in Assessing Social Skills}

Social skills are part of the affective domain. Affective is a quality that shows the typical way someone expresses feelings or emotions [29]. Kratwohl [30] and Rimland [31] say that teachers rarely do affective assessment. Even research found that although almost all educators assessed the cognitive domain, only $7 \%$ assessed the affective domain.

To find out the factors that cause teachers' difficulties in assessing social skills, researchers use the following items in the questionnaire given to respondents.

Table 2. Factors that cause difficulties in assessing social skills

\begin{tabular}{|l|l|}
\hline No & Items \\
\hline 1 & Understanding of the social skills construct \\
\hline 2 & Understanding of social skills indicators \\
\hline 3 & Use of various social skills assessment methods \\
\hline 4 & Availability of social skills assessment instruments \\
\hline 5 & Adequacy of assessment time at school \\
\hline 6 & Teacher and student ratio \\
\hline
\end{tabular}

Respondents were asked to give a score of 1-4 of all items, where $1=$ very poor, $2=$ poor, $3=\operatorname{good}, 4=$ very good. Respondents' answers to these six items were visualized in the form of the figure below.

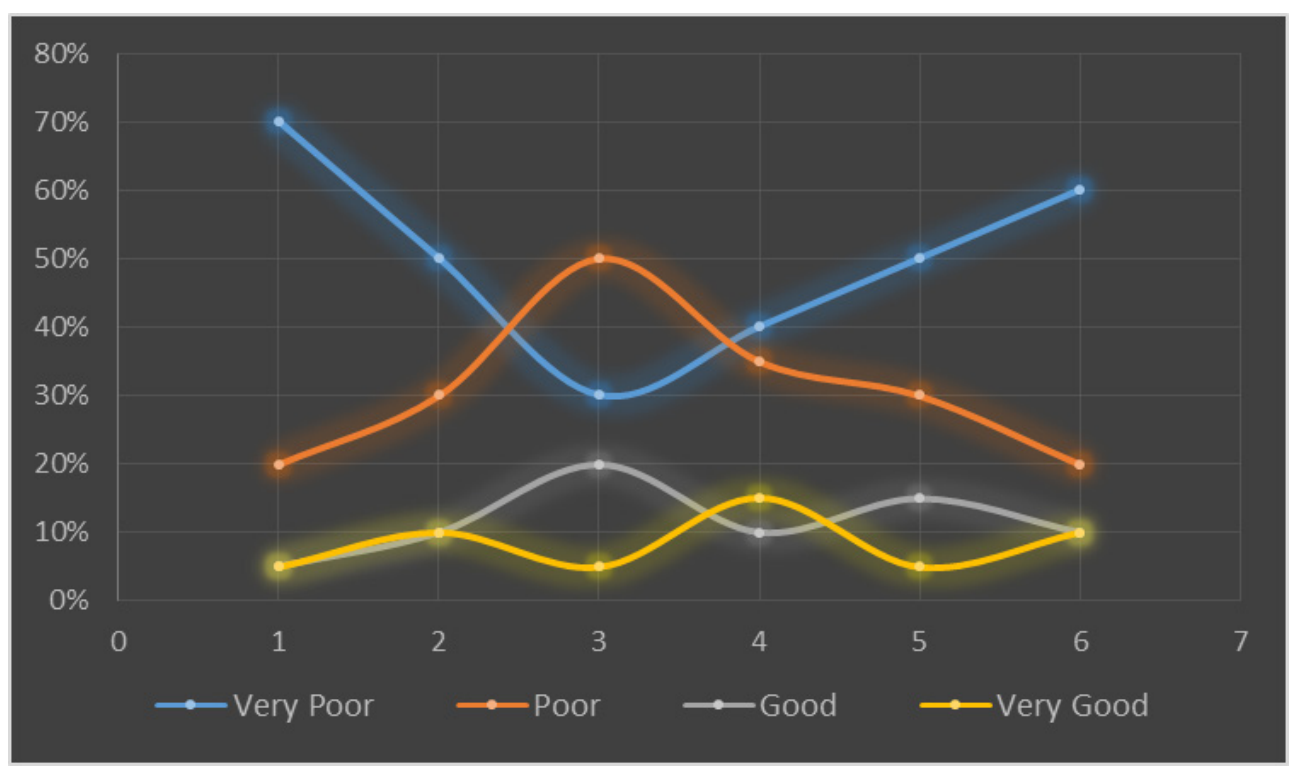

Figure 4. Factors that cause difficulties in assessing social skills 
Based on Figure 4 above, information is obtained that $30 \%$ to $70 \%$ of respondents answered very poor for all items in question. While $20 \%$ to $50 \%$ of teachers answered poor. Other, only $1 \%-20 \%$ of respondents answered very good and good for all items. The questionnaire data above was strengthened by data from in-depth interviews with respondents, as illustrated in the following interview quotes.

"Assessing attitude in face-to-face time for 2 hours lessons is difficult to do because of more attitude on the process ..." (S11, S17)

"I assessed students' attitudes by observing their behavior during class ..." (S8, S14)

Based on the above interview quotation, there are at least two pieces of information obtained, and the first teacher has difficulty in assessing the social skills of students due to time constraints. Secondly, teachers are not very familiar with attitude assessment techniques. In fact, in addition to observation techniques (observation) conducted by the teacher, some attitude assessment techniques that can be used is peer assessment and self-assessment.

The first problem faced by teachers regarding the limitation of time in school to assess students' attitudes authentically can be overcome by involving parents as a teacher partner in assessing students' attitudes. This model of assessment has been developed by Dodge, McClaskey, \& Feldman [26], an assessment involving parents to know the social skills of students. This assessment model can also detect the background of the attitude shown by the students. The introduction of attitudinal and social skills assessment techniques can be done by teachers to broaden their insights and knowledge about the types of assessment techniques already in place. So it is not only fixed on the use of one method but can be combined with different techniques in different circumstances.

"For the overall assessment in Social Studies, I only use daily tests and semester reactions ..." (S5, S20)

"Students who often do trouble in the classroom I consider as students who do not have social skills..."

The cognitive assessment measures students' knowledge and understanding of the material that has been taught. The results of this assessment serve as a basis for assigning good or bad value. Although the information obtained from the test instrument used is valid, reliable, and useful for rating purposes, it does not necessarily determine students' success. Some studies have even found that students' success is more determined by motivation for subjects, attitudes, independence, and self-confidence [32]. These variables are part of the affective domain.

In addition to the results of interviews with the subject, several things can also be revealed about the reasons why social skills are rarely done. Many educators are still questioning the urgency and importance of social skills to be assessed. They argue that social skills are the cognitive area, so they do not need to be explicitly taught or assessed. At that time, educators have difficulty in teaching and assessing social skills. This is because social skills are concepts that cannot be observed directly. Attitudes and values are internal states that cannot always be judged in the same way as in cognitive domains, so educators need more creativity.

\section{Conclusions}

Social skills affect many aspects of children, so it is necessary to be taught. The teaching of social skills is not enough to ensure that students have such capabilities. Therefore, it is also required mastery of techniques in assessing the social skills of students so that teachers can easily detect children who have social problems, both at school and home.

Social Studies is a field that not only teaches social knowledge but also teaches more applicable values that students can apply in their life. These values are social skills, which are socially acceptable behaviors and govern how one interacts with others and the environment.

Although social skills are acknowledged as very important and have been taught in Social Studies lessons as applicative knowledge, Social Studies teachers still have difficulties in assessing students' social skills. This difficulty then leads to the abandonment of social skills, so that students who experience social problems are difficult to detect.

The results of this study indicate that there are at least several factors that cause teachers' difficulties in assessing students' social skills. First, Social Studies teachers' educational qualifications. The changes of the national education curriculum in 2006 and 2013 require teachers with social science educational qualifications to teach Social Studies, whereas the Social Studies is an integration of the social sciences, it is not entirely the same as the social sciences. The research data shows that all social studies teachers have educational qualifications from diverse social sciences, and none of them have educational requirements in the field of social studies. This is a major factor causing difficulties in assessing social skills.

Second, teachers have not been able to identify social skills materials in Social Studies, and tend to assume that social skills are the domain of Civics and Religion lessons. Third, most teachers rarely or never do core activities in learning social skills, for example, in planning, implementing, and assessing social skills.

Fourth, teachers are not familiar with the constructs and social skills indicators. Teachers also have few choices for social skills assessment instruments. The success of social skills assessment cannot be separated from the teacher and student's ratio, where teachers will find it very difficult to assess social skills to many students at once.

Based on the findings in this study, some suggestions 
that need to be made include: social skills must be the core of social studies, social studies teachers must have appropriate educational qualifications so that social studies teachers do not experience difficulties in identifying social skills material. Finally, the development of social skills assessment instruments needs to be continued to obtain the most appropriate measurement tools according to the conditions of students.

\section{Acknowledgements}

The author would like to thank the Indonesia Endowment Fund for Education (LPDP) for funding this research.

\section{REFERENCES}

[1] K. M. Kemple, "Social Studies, Social Competence and Citizenship in Early Childhood Education : Developmental Principles Guide Appropriate Practice," Early Child. Educ. J., 2016.

[2] A. A. Ismail, T. Sulaiman, and S. Roslan, "Models of relationship between emotional, spiritual, physical and social intelligence, resilience and burnout among high school teachers," Univers. J. Educ. Res., vol. 8, no. 1 A, pp. $1-7,2020$.

[3] S. Mendo-Lázaro, B. L. del Barco, E. Felipe-Castaño, M. I. P. del Río, and V. Palacios-García, "Assessment of social skills of students of social education | Evaluación de las habilidades sociales de estudiantes de Educación Social," Rev. Psicodidact., vol. 21, no. 1, pp. 139-156, 2016.

[4] T. Morris, M. McGuire, and B. Walker, "Integrating social studies and social skills for students with emotional and behavioral disabilities: A mixed-methods study," J. Soc. Stud. Res., vol. in press, 2017.

[5] C. Sahin, "An Evaluation of Teachers' Perceptions of Teaching Social Skills to Fifth Grade Students within the Scope of Social Studies Lessons," Int. J. Progress. Educ., vol. 6, no. 1, pp. 28-46, 2010.

[6] J. Gottman, "Teaching Social Skills to Isolated Children," $J$. Anorm. child psycology, vol. 4, no. 2, pp. 179-197, 1976.

[7] J. L. Matson and J. Wilkins, "Psychometric testing methods for children's social skills," Res. Dev. Disabil., vol. 30, no. 2, pp. 249-274, 2009.

[8] K. Bikos, "Moral Judgments of Sociometrically Neglected Children Concerning Their Bullying Experiences in the First Grade .," Int. J. Humanit. Soc. Sci., vol. 2, no. 9, pp. 23-33, 2012.

[9] M. E. Derosier and M. E. Derosier, "Journal of Clinical Child \& Adolescent Psychology Building Relationships and Combating Bullying: Effectiveness of a School-Based Social Skills Group Intervention Building Relationships and Combating Bullying : Effectiveness of a School-Based Social Skill," no. August 2013, pp. 37-41, 2010.
[10] L. N. Jenkins, M. K. Demaray, S. S. Fredrick, and K. H. Summers, "Associations Among Middle School Students' Bullying Roles and Social Skills," J. Sch. Violence, vol. 15, no. 3, pp. 259-278, 2016.

[11] F. M. Wang, J. Q. Chen, W. Q. Xiao, Y. T. Ma, and M. Zhang, "Peer Physical Aggression and Its Association With Aggressive Beliefs, Empathy, Self-Control, and Cooperation Skills Among Students in a Rural Town of China," J. Interpers. Violence, vol. 27, no. 16, pp. 3252 3267, 2012.

[12] Syaiful, Kamid, Muslim, N. Huda, A. Mukminin, and A. Habibi, "Emotional quotient and creative thinking skills in mathematics," Univers. J. Educ. Res., vol. 8, no. 2, pp. 499$507,2020$.

[13] I. R. Karkada, U. John, D. Arnold, and Z. Arifin, "Relationship of Emotional Intelligence and Academic Performance among Medical Students : Systematic Review," vol. 8, no. 1, pp. 72-79, 2020.

[14] Y. Susilowati, "The Relationship between Students, Attitudes toward Lecturer Teaching Methods and Learning Environment with Achievement Motivation ( Descriptive Study of Management Students of STIE Dharma Agung )," vol. 8, pp. 65-71, 2020.

[15] L. K. Elksnin and N. Elksnin, "Teaching Social Skills to Students with Learning and Behavior Problems," Interv. Sch. Clin., vol. 33, no. 3, pp. 131-140, 1998.

[16] F. M. Gresham, S. N. Elliott, M. J. Vance, and C. R. Cook, "Comparability of the Social Skills Rating System to the Social Skills Improvement System: Content and psychometric comparisons across elementary and secondary age levels.," Sch. Psychol. Q., vol. 26, no. 1, pp. $27-44,2011$.

[17] N. Tsangaridou, E. Zachopoulou, J. Liukkonen, A. Gråstén, and M. Kokkonen, "Developing preschoolers' social skills through cross-cultural physical education intervention," Early Child Dev. Care, vol. 184, no. 11, pp. 1550-1565, 2014.

[18] D. L. Espelage, C. A. Rose, and J. R. Polanin, "Social-Emotional Learning Program to Promote Prosocial and Academic Skills Among Middle School Students With Disabilities," Remedial Spec. Educ., vol. 37, no. 6, pp. 323$332,2016$.

[19] M. K. Demaray et al., "Social Skills Assessment: a Comparative Evaluation of Six Published Rating Scales," Sch. Psychol. Rev. Waksman Soc. Ski. Rat. Scale (WSSRS; Waksman, vol. 24, no. 4, 1995.

[20] J. Ding and Y. Sugiyama, "Development of a scale to assess Chinese college student's social skills in physical education classes," vol. 38, pp. 11-19, 2016.

[21] F. M. Gresham, S. N. Elliott, P. L. Newcomer, and S. N. El, "Social Skills Assessment Technology for LD Students Comments On The Interagency Committee On Learning Disabilities' Definition Of Learning Disabilities Social Skills Assessment Technology For Ld Students," Source Learn. Disabil. Q., vol. 12, no. 2, pp. 141-152, 1989.

[22] K. D. Green and R. Forehand, "Assessment of children's social skills: A review of methods," J. Behav. Assess., vol. 2, no. 2, pp. 143-159, 1980. 
[23] S. N. Elliot, S. M. Sheridan, S. N. Elliott, S. M. Sheridan, and F. M. Gresham, "Assessing and Treating Social Skills Deficits: A Case Study for the Assessing and Treating Social Skills Deficits: A Case Study for the Scientist-Practitioner," vol. 27, no. November, pp. 197-222, 1989.

[24] J. K. Luisella, J. C. McCarty, J. Coniglio, C. Zorilla-Ramirez, and R. F. Putnam, "Social skills assessment and intervention," J. Appl. Sch. Psychol., vol. 21, no. September, pp. 21-38, 2005.

[25] R. E. Riggio, “Assessment of basic social skills.," J. Pers. Soc. Psychol., vol. 51, no. 3, pp. 649-660, 1986.

[26] K. a Dodge, C. L. McClaskey, and E. Feldman, "Situational approach to the assessment of social competence in children.," J. Consult. Clin. Psychol., vol. 53, no. 3, pp. 344-353, 1985.

[27] E. W. Ross, Social Studies Curriculum, Third. Albany: State University of New York Press, 2006.

[28] R. C. Wade, The Teaching for Social Justice Series. New York: Teachers College Press, 2007.

[29] Anderson, Lorin. W., 1981. Assessing Affective Characteristics in the Schools. Boston: Allyn and Bacon.

[30] D. R. Krathwohl, B. S. Bloom, \& B. B. Masia. "Taxonomy of educational objectives, the classification of educational goals". Handbook II: Affective domain. New York: David McKay Co, Inc.1964

[31] E. Rimland. "Assessing Affective Learning Using a Student Response System". Baltimore: Libraries and the Academy. Vol. 13, No. 4: 385-401, 2013.

[32] P. Saxon \& B. Calderwood, "Affective Assessment for Developmental Students," Part 1. Research in Developmental Education. Appalachian State University. Vol. 22, Issue 1, 2008. 